\title{
Finite Element Analysis of Anchor Leg Improved Trough Embedded Parts Based on ABAQUS
}

\author{
Xin Huang ${ }^{1}$, Yunfan $\mathrm{Gu}^{1, *}$, Baocun $\mathrm{Shi}^{1}$, Xin Chen ${ }^{1}$, and Wei Jiang ${ }^{1}$ \\ ${ }^{1}$ School of Architectural Engineering, Nanjing Institute of Technology, Nanjing, 211167, China
}

\begin{abstract}
Reasonable and accurate simulations of failure behaviors of steel-concrete composite members with trough embedded parts is of great significance for the study of joint failure mechanism of prefabricated components in assembled buildings. Based on the implicit solution module of ABAQUS, the anchor legs of 5234 trough embedded parts are redesigned. The cylindrical anchor legs are designed as anchor plates with different diameter holes. The finite element model of the anchor leg of improved 5234 trough embedded parts and that of concrete are established. The mechanical properties of the specimens under bending and shear failure are simulated. And take a research on the improved trough embedded parts. The results show that the ultimate stress of concrete and the ultimate stress of embedded parts decrease first, then increase and then decrease with the increase of the diameter of circular hole, and the displacement of anchor leg of embedded parts decreases first and then increases with the increase of the diameter of circular hole. When the diameter of circular hole is $10.0 \mathrm{~mm}$, the ultimate stress of concrete, the ultimate stress of embedded parts and the displacement of anchor leg are the smallest, and the mechanical properties of embedded parts are improved the most.
\end{abstract}

\section{Introduction}

In recent years, with the rapid development of assembled buildings, embedded parts, as one of the connections between steel-concrete structures, have been gradually used in bridges, wharfs and some super high-rise buildings in a wider range of application. In the existing technology, various mechanical properties of anchor rod embedded parts are tested and analyzed by finite element method. Wang Qingxiang[1] and others carried out pure shear and pull-shear tests on large diameter anchor rod embedded parts. The results showed that the failure mode of anchor rod embedded parts was pull-off under composite stress and had good ductility; Tang Ruirui [2] and others studied the residual bearing capacity of anchor rod embedded parts after fire and the bond performance between steel bar and concrete, and the research showed that the failure mode of anchor rod embedded parts was pull-off under composite stress. The bearing capacity of anchor rod embedded parts and bond strength of steel bar decrease with the increase of the highest temperature experienced. The results of ABAQUS simulations of temperature field are on the high side, and the simulation results are on the safe side.

The mechanical properties and calculation analysis of embedded parts are studied in the current literature. However, with the requirements of engineering economy and mechanical properties of embedded parts, it is necessary for us to redesign the size of conventional embedded parts to improve their performance in some aspects. In existing patents, Bai Baokun [3] improves its drawing strength by bending the anchor legs of existing embedded parts into a single plate and punching holes on the side walls. It is of great significance to redesign the structure of embedded parts for the performance study and practical engineering application of embedded parts.

\section{Model design}

In this paper, mainly through structural design of anchor legs of 5234 trough embedded parts, the existing cylindrical anchor legs are designed as anchor plates with different diameter circular holes. The effects of different diameter circular holes on mechanical properties of 5234 trough embedded parts under bending and shear loads $(160 \mathrm{kN})$ are studied, and compared with solid anchor legs, the most suitable diameter of the round hole on the anchor leg of improved 5234 trough embedded parts is studied.Based on the implicit solution module of finite element analysis software ABAQUS, this paper establishes five finite element models of trough embedded parts, and analyses the stress performance of anchor legs of improved 5234 trough embedded parts with hollow circular holes of different diameter under bending and shear loads.

When concrete is poured, cement mortar or concrete is also poured into hollow round holes in anchor legs of trough embedded parts. The grouted cement mortar or concrete in hollow circular holes is connected with concrete specimens to form a whole. The whole concrete can not only increase the flexural performance of anchor legs of anchor rod embedded parts again, but also

\footnotetext{
* Corresponding author: 15195858185@163.com
} 
increase the bonding performance between anchor legs and concrete. Therefore, five groups of 5234 trough embedded parts are designed. The hollow circular hole diameters of anchor legs are $0.0 \mathrm{~mm}, 8.0 \mathrm{~mm}, 10.0 \mathrm{~mm}$, $15.0 \mathrm{~mm}$ and $20.0 \mathrm{~mm}$, respectively. The trough steel dimensions, anchor legs and the position dimensions of circular hole of 5234 trough embedded parts are shown in Table 1 and fig 1 and 2.

Table 1. 5 group trough embedded parts improved design size table

\begin{tabular}{|c|c|c|c|c|c|c|}
\hline $\begin{array}{c}\text { Numbe } \\
r\end{array}$ & $\begin{array}{c}\text { Chan } \\
\text { nel } \\
\text { steel } \\
\text { model }\end{array}$ & $\begin{array}{l}\text { Anchor leg } \\
\text { Length * } \\
\text { width * } \\
\text { thickness }\end{array}$ & $\begin{array}{c}\text { Numb } \\
\text { er of } \\
\text { ancho } \\
\text { r legs }\end{array}$ & $\begin{array}{c}\text { Number } \\
\text { of } \\
\text { circular } \\
\text { holes }\end{array}$ & $\begin{array}{c}\text { Circular } \\
\text { hole } \\
\text { diameter }\end{array}$ & $\begin{array}{c}\text { Circula } \\
\text { r hole } \\
\text { positio } \\
n\end{array}$ \\
\hline 1 & \multirow{5}{*}{$\begin{array}{c}5234 \\
\text { model }\end{array}$} & \multirow{5}{*}{$\begin{array}{c}100 \mathrm{~mm}^{*} 30 \mathrm{~m} \\
\mathrm{~m} * 5 \mathrm{~mm}\end{array}$} & \multirow{5}{*}{2} & \multirow{5}{*}{2} & $0.0 \mathrm{~mm}$ & \multirow{5}{*}{$\begin{array}{c}\text { See } \\
\text { details }\end{array}$} \\
\hline 2 & & & & & $8.0 \mathrm{~mm}$ & \\
\hline 3 & & & & & $10.0 \mathrm{~mm}$ & \\
\hline 4 & & & & & $15.0 \mathrm{~mm}$ & \\
\hline 5 & & & & & $20.0 \mathrm{~mm}$ & \\
\hline
\end{tabular}

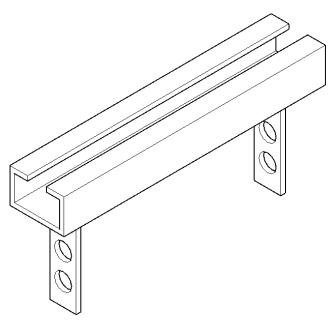

Fig. 1. Schematic diagram of trough embedded parts with improved anchor legs.
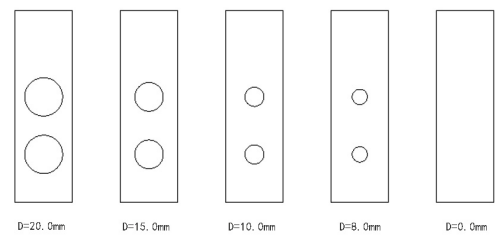

Fig. 2. Size design of anchor leg circular hole.

\section{Finite element simulation analysis}

\subsection{Constitutive model of materials}

Three concrete constitutive models [4] are provided in ABAQUS:1) Brittle cracking model, 2) Smeared cracking model, 3) Damaged plasticity model. When applied to simulate structures subjected to monotonic, reciprocating and dynamic loading conditions, the damaged plasticity model is easier to converge and the results are more accurate compared with the other two models. Therefore, the damage plasticity model is adopted in the calculation. The damage plasticity model is based on the uniaxial constitutive relationship of concrete. In this paper, the stress-strain relationship proposed by Professor Guo Zhenhai of Tsinghua University is adopted. As shown in Fig. 3, the expression of the compression part is:

$$
y=\left\{\begin{array}{lr}
\mathrm{A} x+(3-2 \mathrm{~A}) x^{2}+(\mathrm{A}-2) x^{3} & (0 \leq x \leq 1) \\
x \cdot\left[\mathrm{a}(x-1)^{2}+x\right]^{-1}, & (x>1)
\end{array}\right.
$$

In the formula: $\mathrm{A}$ is the ratio of the initial elastic modulus of concrete to the secant modulus of concrete at the peak point, i.e. $\mathrm{A}=\mathrm{E} 0 / \mathrm{Ep}$. The descending section a can indicate the steepness of the descending section to a certain extent, i.e. it is positively correlated with the absolute value of the rigidity of the descending section. The values of $\mathrm{A}$ and $\mathrm{a}$ are referenced in $[6] ; \mathrm{x}=\varepsilon / \varepsilon \mathrm{c}$; $\mathrm{y}=\sigma / \mathrm{fc} ; \mathrm{fc}$ is the compressive strength of concrete, taking 34.9 $\mathrm{MPa} . \varepsilon \mathrm{c}$ is the peak strain corresponding to fc , taking 0.0023 .

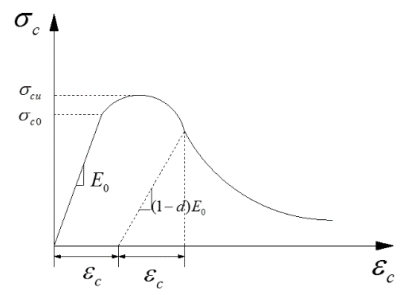

(a)uniaxial compression

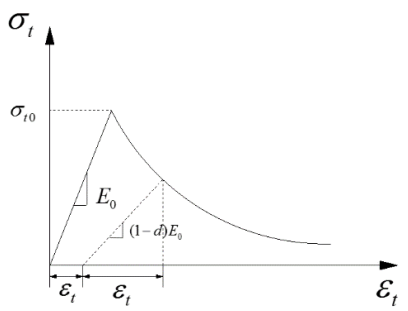

(b)uniaxial tension

Fig. 3. Stress-strain curve of concrete.

The expression of the tension part is:

$$
y=\left\{\begin{array}{lc}
1.2 x-0.2 x^{6} & , \\
x \cdot\left[\gamma(x-1)^{1.7}+x\right] & (0 \leq x \leq 1) \\
& (x>1)
\end{array}\right.
$$

In the formula, $x=\varepsilon / \varepsilon t ; y=\sigma / f t ; f t$ is the compressive strength of concrete; $\varepsilon t$ is the peak compressive strain corresponding to $\mathrm{ft}$; and $\gamma$ is the parameter value of curve softening section.

In this paper, the elastic-plastic ideal bilinear model is used for the constitutive analysis of Q235 embedded parts and universal beam. The initial modulus of elasticity is $2.09 \times 106 \mathrm{MPa}$, Poisson ratio is 0.3 and yield strength is $235 \mathrm{MPa}$.

\subsection{Interactions in materials}

In order to make the universal beam and the embedded parts work together in the analysis engineering, the universal beam and the contact part of the embedded part are bound and restrained. A reference point is placed on the upper surface of the universal beam and is coupled with the upper surface to be applied to load. In the simulation analysis, the contact pairs are set at the contact parts between concrete and steel. Using surface to surface contact,the steel is set as the main surface and the concrete is set as the slave surface. The slip formula adopts the finite slip which allows the relative slip and rotation of any size between the contact surfaces [6]. Tangential behaviors and normal behaviors are set as the main contact attributes. Penalty friction formula is used for tangential behaviors of contact.Friction coefficient(Reference [7]) takes 0.4, and "hard" contact is used for normal behaviors. 


\subsection{Determine the boundary conditions.}

In order to define the boundary conditions more accurately, three degrees of freedom constraints are applied to the lower surface of the concrete block when in finite element analysis, and displacement constraints are applied to the side of the concrete block and the side of the universal beam.

\subsection{Applied load}

In the simulation, the concentrated force load is applied to the reference point on the upper surface of universal beam, and the concentrated force is $160 \mathrm{kN}$. The universal beam transfers the force to the embedded part through the contact with the embedded part, which causes the anchor leg to displace. In the process of model analysis, the same load is applied to the five models, and the final model results converge.

\subsection{Unit type selection and mesh partition.}

ABAQUS provides abundant types of elements. In order to make the model more convergent, according to the mechanical characteristics of the model, the 8-node hexahedron reduced integral solid element C3D8R is used in this paper. The contact between embedded parts and concrete surface is a highly contact non-linear problem. In the contact problem, the slave mesh should be finer than the main mesh. [8]. In order to make the results more accurate, the size of concrete element in contact part should be $7 \mathrm{~mm}$, and the size of embedded parts element should be $7.5 \mathrm{~mm}$. Check the grid.The grid quality is good,no warnings and mistakes.

\section{Finite element analysis results}

According to the results of finite element analysis,compare the deformation and stress nephograms of five kinds of trough embedded parts with improved anchor legs and the stress nephograms of concrete specimen, the research on the stress and deformation of concrete and embedded parts can be more intuitive. From the results of finite element analysis and Figure 4, it can be seen that the maximum deformation of trough embedded parts occur at the junction of T-bolt and channel steel, the phenomenon of channel steel crimping is obvious, and the maximum stress area of concrete surface is at the lower side of the trough embedded parts. When the trough embedded parts are subjected to bending and shearing, the T-bolt will exert pulling force on the upper side of the channel steel and exert relatively large pressure on the lower side of the channel steel. When the pull-out force applied to the upper side of channel steel exceeds the yield strength of steel, the groove mouth of channel steel yields; when the pressure applied to the lower side of channel steel exceeds the ultimate compressive strength of concrete, the concrete on the lower side of the embedded part will be crushed, resulting in the destruction of concrete specime

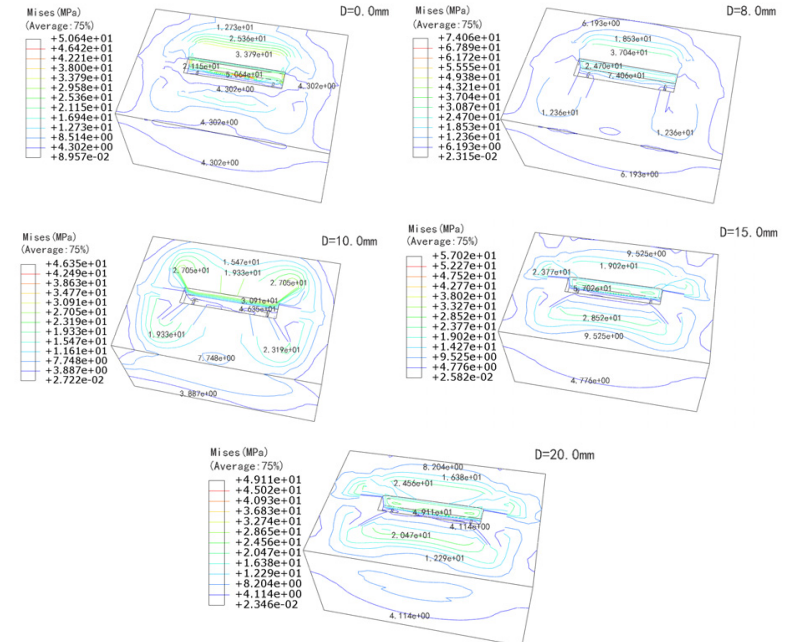

Fig. 4. Five groups of concrete specimen stress diagram.

The limit stress and peak strain values of the 5 sets of specimens are shown in Table 2. From the concrete ultimate stress, the deformation and the ultimate stress of the embedded parts of the five groups of specimens in Table 2, it can be seen that the ultimate stress of the concrete and the ultimate stress of the embedded parts after loading decreases first, then increases and then decreases with the increase of the diameter of the circular hole, and the displacement of the anchor leg of the embedded parts decreases first and then increases with the increase of the diameter of the circular hole. When the diameter of the circular hole is $10.0 \mathrm{~mm}$, the ultimate stress of concrete, the ultimate stress of embedded parts and the displacement of anchor leg are the smallest, of which the ultimate stress of concrete is 46.35 $\mathrm{MPa}$, the ultimate stress of embedded parts is 316.0 MPa, and the maximum displacement of anchor leg of embedded parts is $5.14 \mathrm{~mm}$. At this time, the mechanical properties of embedded parts reach the maximum improvement at present.

Table 2. Limit stress and peak strain of 5 sets of specimens

\begin{tabular}{|c|c|c|c|c|}
\hline Number & $\begin{array}{c}\text { Circular } \\
\text { hole } \\
\text { diameter }\end{array}$ & $\begin{array}{c}\text { Ultimate } \\
\text { stress of } \\
\text { concrete } \\
\text { /MPa }\end{array}$ & $\begin{array}{c}\text { Limit } \\
\text { stress of } \\
\text { embedded } \\
\text { parts/MPa }\end{array}$ & $\begin{array}{c}\text { Peak } \\
\text { displacement } \\
\text { of embedded } \\
\text { parts/mm }\end{array}$ \\
\hline 1 & $0.0 \mathrm{~mm}$ & 50.64 & 448.3 & 10.94 \\
\hline 2 & $8.0 \mathrm{~mm}$ & 74.06 & 408.4 & 8.83 \\
\hline 3 & $10.0 \mathrm{~mm}$ & 46.35 & 316.0 & 5.14 \\
\hline 4 & $15.0 \mathrm{~mm}$ & 57.02 & 359.7 & 7.32 \\
\hline 5 & $20.0 \mathrm{~mm}$ & 49.11 & 373.5 & 7.39 \\
\hline
\end{tabular}

The comparison of displacement load-curve measured by five groups of specimens simulated by finite element method is shown in Fig. 5. From the figure, it can be seen that the trough embedded parts have obvious elastic and plastic stages, and when the diameter of the circular hole is $10.0 \mathrm{~mm}$, the mechanical properties of the specimens are the best. 


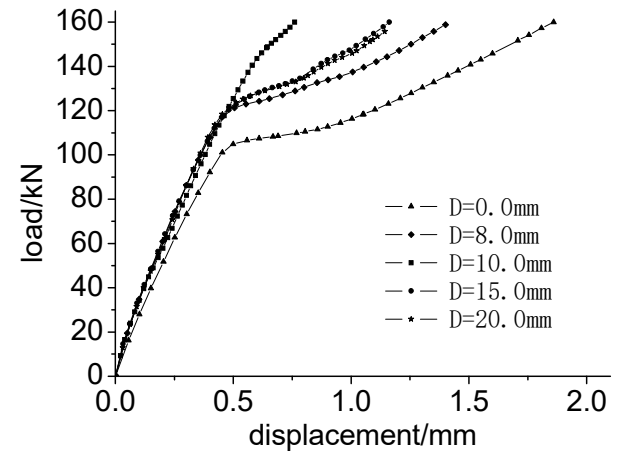

Fig. 5. Comparison of load displacement curves between 5 groups of specimens.

\section{Conclusion}

- The maximum stress of trough embedded parts of each specimen is mainly at the connection between $\mathrm{T}$ bolts and channel steel. The maximum stress is in the range of 370-450 MPa. The trough embedded parts have completely entered the plastic state. The maximum concrete stress of each specimen is mainly at the end of anchor leg, and the maximum stress is in the range of 45$75 \mathrm{MPa}$. The concrete has reached the compressive limit.

- From the results of finite element analysis, it can be seen that the ultimate stress of concrete and embedded parts after loading decreases first, then increases and then decreases with the increase of the diameter of circular hole, and the displacement of anchor leg of embedded parts decreases first and then increases with the increase of the diameter of circular hole.

- By comparing the results of finite element analysis of five groups of specimens, it is concluded that when the diameter of circular hole is $10.0 \mathrm{~mm}$, the ultimate stress of concrete, the ultimate stress of embedded parts and the displacement of anchor leg are the smallest, in which the ultimate stress of concrete is $46.35 \mathrm{MPa}$, the ultimate stress of embedded parts is $316.0 \mathrm{MPa}$, and the maximum displacement of embedded Parts'anchor leg is $5.14 \mathrm{~mm}$. The mechanical properties of embedded parts reach the maximum improvement now.

\section{Acknowledgments}

The authors are grateful for the financial support from Nanjing Institute of Engineering 2018 Challenge Cup Cultivation Project (TP20180006).

\section{References}

1. Q.X.WANG,Y.G.ZHU,Experimental study on large diameter anchor rod embedded parts under pure she ar and tension shear, J.Build.Str,29,281-286 (2008)

2. R.R.TANG, Research on residual bearing capacity a nd bond slip property of anchored tendon embedded parts after overfire,Beijing University Of Civil Engi neering And Architecture(2014)
3. B.K.BAI., Trough embedded parts,CN103074940A (2013)

4. Hibbitt, Karlsson, Sorensen,ABAQUS/Standard Use $r$ Subroutines Reference Manual (The Pennsylvania State University, The United States, 1998)

5. Z.H.GUO,X.D.SHI,Reinforced Concrete Theory an $d$ Analys(Tsinghua University Press, Beijing,2003)

6. J.C.WANG,Y.K.CHEN,Application of ABAQUS in Civil Engineering(Zhejiang University Press,Hangz hou,2006)

7. Z.F.CHEN,C.G.LI, J.L.GUO,Research on Contact P roblem about Steel Plate and Concrete Based on AB AQUS,Urb.Road.B.\& F.Contr,5,201-203+6 (2006)

8. J.F.CAO,Y.P.SHI,ABAQUS finite element analysis $f$ requently asked questions (China machine press,200 9) 